\title{
Intestinal Ultrasound in Inflammatory Bowel Disease: A Valuable and Increasingly Important Tool
}

\author{
Catarina Frias-Gomes $^{a} \quad$ Joana Torres ${ }^{a, b} \quad$ Carolina Palmela ${ }^{a}$ \\ ${ }^{a}$ Gastroenterology Division, Surgical Department, Hospital Beatriz Ângelo, Loures, Portugal; \\ ${ }^{b}$ Faculdade de Medicina da Universidade de Lisboa, Lisbon, Portugal
}

Keywords

Intestinal ultrasound · Diagnosis - Disease activity ·

Monitoring $\cdot$ Therapy response $\cdot$ Point-of-care

\section{Abstract}

Background: Intestinal ultrasound is emerging as a non-invasive tool for monitoring disease activity in inflammatory bowel disease patients due to its low cost, excellent safety profile, and availability. Herein, we comprehensively review the role of intestinal ultrasound in the management of these patients. Summary: Intestinal ultrasound has a good accuracy in the diagnosis of Crohn's disease, as well as in the assessment of disease activity, extent, and evaluating diseaserelated complications, namely strictures, fistulae, and abscesses. Even though not fully validated, several scores have been developed to assess disease activity using ultrasound. Importantly, intestinal ultrasound can also be used to assess response to treatment. Changes in ultrasonographic parameters are observed as early as 4 weeks after treatment initiation and persist during short- and long-term follow-up. Additionally, Crohn's disease patients with no ultrasound im- provement seem to be at a higher risk of therapy intensification, need for steroids, hospitalisation, or even surgery. Similarly to Crohn's disease, intestinal ultrasound has a good performance in the diagnosis, activity, and disease extent assessment in ulcerative colitis patients. In fact, in patients with severe acute colitis, higher bowel wall thickness at admission is associated with the need for salvage therapy and the absence of a significant decrease in this parameter may predict the need for colectomy. Short-term data also evidence the role of intestinal ultrasound in evaluating therapy response, with ultrasound changes observed after 2 weeks of treatment and significant improvement after 12 weeks of follow-up in ulcerative colitis. Key Messages: Intestinal ultrasound is a valuable tool to assess disease activity and complications, and to monitor response to therapy. Even though longer prospective data are warranted, intestinal ultrasound may lead to a change in the paradigm of inflammatory bowel disease management as it can be used in a point-of-care setting, enabling earlier intervention if needed.
C 2021 Sociedade Portuguesa de Gastrenterologia Published by S. Karger AG, Basel
Correspondence to:

Carolina Palmela, palmela.carolina@ gmail.com karger@karger.com www.karger.com/pjg

Karger $\stackrel{\text { ' }}{5}$

BOPEN ACCESS
C 2021 Sociedade Portuguesa de Gastrenterologia Published by S. Karger AG, Basel

This is an Open Access article licensed under the Creative Commons Attribution-NonCommercial-4.0 International License (CC BY-NC) (http://www.karger.com/Services/OpenAccessLicense), applicable to the online version of the article only. Usage and distribution for commercial purposes requires written permission. 


\section{Ecografia intestinal na doença inflamatória do intestine: uma ferramenta valiosa e de importância crescente}

\section{Palavras Chave}

Ecografia intestinal - Diagnóstico - Atividade de doença · Monitorização · Resposta à terapêutica · Point-of-care

\section{Resumo}

Contexto: A ecografia intestinal na doença inflamatória intestinal tem ganho importância crescente como exame não invasivo para monitorizar a atividade de doença, pelos seus custos reduzidos, excelente perfil de segurança e disponibilidade. Neste artigo realizamos uma revisão sobre o papel da ecografia intestinal no manejo destes doentes. Sumário: Na doença de Crohn, a ecografia intestinal tem uma boa acuidade no diagnóstico, avaliação da atividade e extensão da doença, assim como na avaliação de complicações, como estenoses, fístulas e abcessos. Apesar de não estarem validados, vários scores têm sido desenvolvidos para avaliar a atividade de doença. É de realçar a importância da ecografia intestinal na avaliação da resposta à terapêutica. A melhoria dos parâmetros ecográficos é observada tão precocemente como quatro semanas e persiste durante o seguimento a curto e longo prazo. Os doentes sem melhoria ecográfica parecem ter uma maior necessidade de intensificação terapêutica, corticóides, internamento ou cirurgia. À semelhança da doença de Crohn, a ecografia intestinal tem uma boa acuidade na avaliação ao diagnóstico, atividade e extensão da doença na colite ulcerosa. Na colite ulcerosa grave, um maior espessamento da parede intestinal à admissão está associado a maior necessidade de terapêutica de resgate e a ausência de melhoria deste parâmetro pode predizer a necessidade de colectomia. A ecografia também permite a avaliação da resposta à terapêutica na colite ulcerosa, com alterações observadas após duas semanas de tratamento e mantendo melhoria significativa após 12 semanas. Mensagemchave: A ecografia intestinal é um método importante para avaliar a atividade de doença, complicações e monitorizar a resposta à terapêutica na doença inflamatória intestinal. Apesar de serem necessários mais estudos prospetivos, a ecografia intestinal pode levar a uma mudança de paradigma no manejo destes doentes, uma vez que pode ser utilizada no momento de prestação de cuidados, permitindo uma intervenção precoce quando necessário.

(C) 2021 Sociedade Portuguesa de Gastrenterologia Published by S. Karger AG, Basel

\section{Introduction}

Objective evidence of bowel inflammation is a key feature in the management of inflammatory bowel disease (IBD) patients, since clinical-based assessment is insufficient to make adequate therapeutic decisions [1]. Endoscopic mucosal healing ( $\mathrm{MH}$ ) has emerged as a major therapeutic endpoint, as it has been associated with longterm clinical remission, steroid-free remission, and reduced risk of surgery $[2,3]$. However, endoscopy is a time-consuming, expensive and invasive technique, not always tolerated by patients. Therefore, a growing interest has risen regarding non-invasive monitoring tools, such as intestinal ultrasound (IUS) and faecal calprotectin (FCal). IUS is a widely available imaging modality associated with low costs, an excellent safety profile, and lack of preparation [4]. It is increasingly recognised as an accurate technique as part of the armamentarium for IBD diagnosis, but also for assessing disease activity and extent, detecting complications, and monitoring response to therapy [5]. Moreover, IUS can be performed in a point-of-care setting, leading to therapy optimisation without delay, allowing repeated evaluations to monitor lesions over time, and even replacing invasive examinations, such as endoscopy [6]. Moreover, due to lack of radiation, good availability, and because it is an easy exam to perform for both patients and physicians, in experienced hands IUS can also replace other crosssectional image modalities, such as computerised tomography (CT) or magnetic resonance (MR) [3]. When compared to other non-invasive monitoring tools such as FCal or C-reactive protein, IUS offers additional information, namely on disease extension, location, severity, and complications [4, 6]. Finally, in an era of shared decision-making with our patients, it is important to consider their acceptance when proposing follow-up examinations. In a recent systematic review, IBD patients preferred non-invasive techniques, particularly IUS, to monitor disease activity, when compared to endoscopy [7].

There is a clear need to consider IUS as a non-invasive monitoring tool in IBD, with recent ECCO-ESGAR recommendations supporting the use of IUS in the diagnosis and management of IBD patients [3]. In this review, we comprehensively discuss the role of IUS for: (a) screening and diagnosis of IBD; (b) evaluating disease activity and postoperative recurrence in Chron's disease (CD); (c) evaluating disease-related complications; and (d) monitoring response to therapy, both in $\mathrm{CD}$ and ulcerative colitis (UC) patients. 

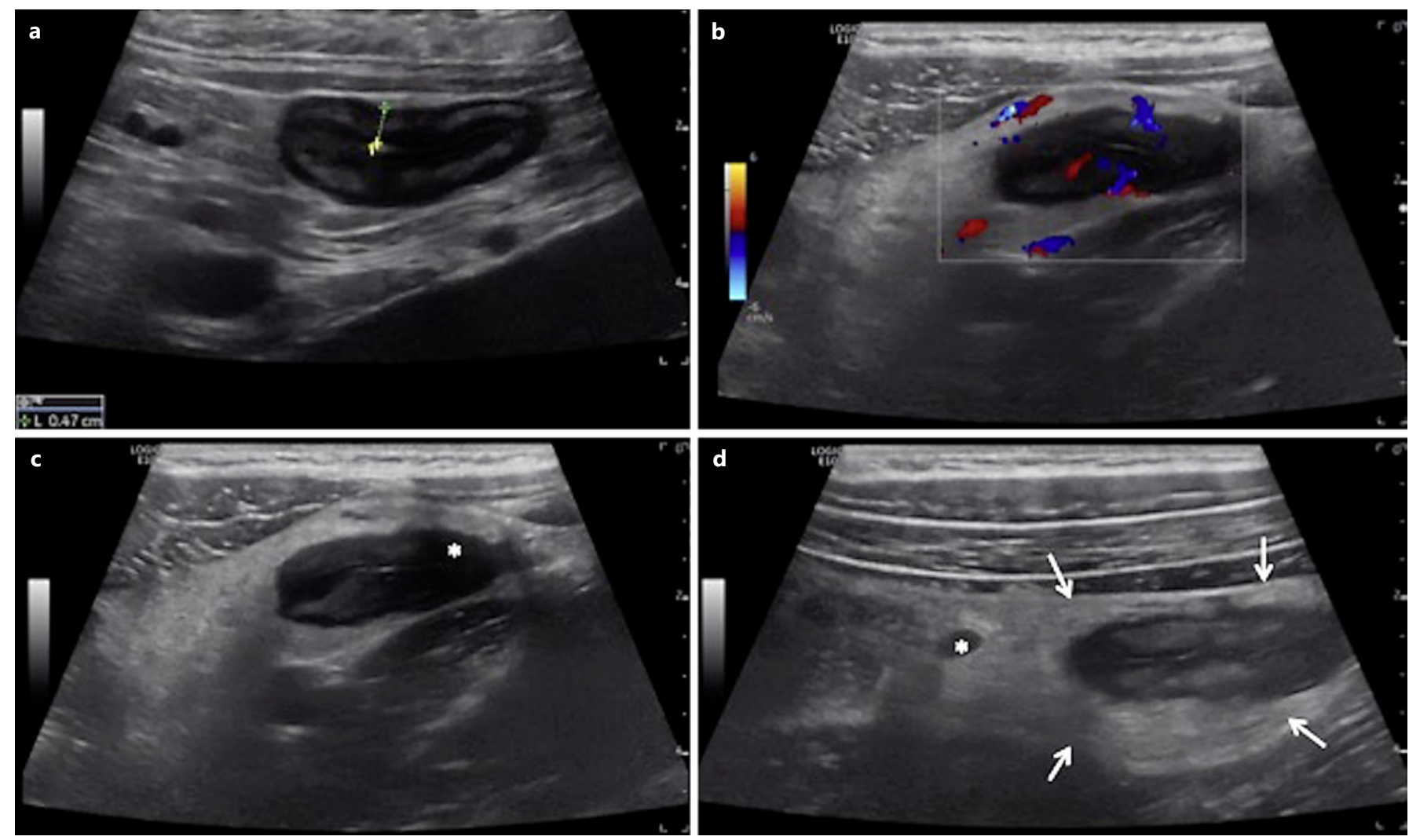

Fig. 1. Examples of IUS parameters. a Measurement of increased BWT $(4.7 \mathrm{~mm})$. b Increased CDF (Limberg score 4). c Areas of focal loss of BWS (asterisk). d Extramural findings, including mesenteric fat proliferation (arrows) and mesenteric lymph node (asterisk).

\section{Screening and Diagnosis of IBD}

IUS has been used as a screening tool in patients with gastrointestinal (GI) symptoms but without severe signs of disease (such as weight loss, anaemia, or elevated FCal), showing a good accuracy to distinguish IBD from irritable bowel syndrome patients in primary care settings [8]. Additionally, in a recent prospective study including 37 patients with low-risk abdominal symptoms, the use of IUS reduced the number of colonoscopies and appointments, improving health service outcomes [9]. Furthermore, GI infections can also mimic IBD. IUS has been shown to be an accurate method in the diagnosis of infectious enteritis when compared to CT or MR, and the major findings include hypoechoic small bowel wall thickening and lymph node enlargement. Similarly, IUS can also detect inflammation in infectious colitis. Importantly, all these IUS features may overlap with IBD, and IUS alone cannot diagnose GI infections. Therefore, an ultrasound control can be performed in these patients to exclude IBD [10].

Intestinal Ultrasound in IBD
The most frequent IUS parameter used to detect intestinal inflammation is bowel wall thickness (BWT; Fig. 1a). Common cut-off values are $2-3 \mathrm{~mm}$ for the small bowel and 3-4 $\mathrm{mm}$ for the colon [11]. Loss of bowel wall stratification (BWS) and increased vascularisation assessed through colour Doppler flow (CDF) are also associated with active inflammation (Fig. 1b, c) [11]. Finally, extramural features are also important, such as mesenteric fat proliferation and lymph nodes (Fig. 1d).

Therefore, IUS can be a very helpful tool for IBD diagnosis. For instance, CD patients at diagnosis should undergo small bowel assessment, either by MR enterography (MRE), IUS, and/or capsule endoscopy. CT enterography is another valid option, though it is associated with radiation exposure [3]. In a systematic review, including 1,558 CD patients, endoscopic, histologic, barium examination, and/or intraoperative findings were used for the reference standard. The overall polled sensitivity of IUS was $88 \%$ and specificity $97 \%$ [12]. When specifically evaluating small bowel disease, the overall sensitivity of IUS ranged from 54 to $93 \%$, with a specificity of $97-100 \%$ [13].

GE Port J Gastroenterol 2022;29:223-239 


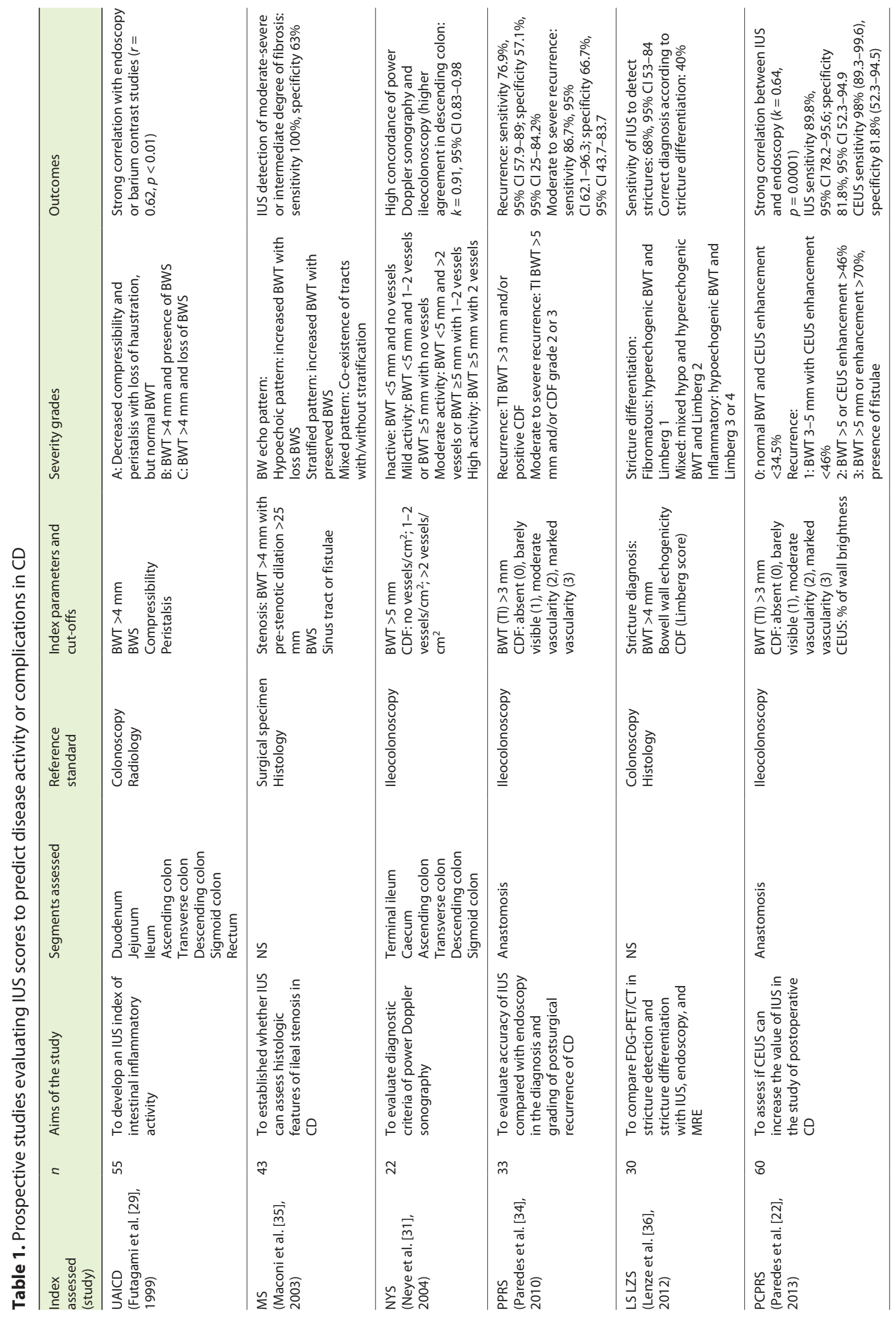




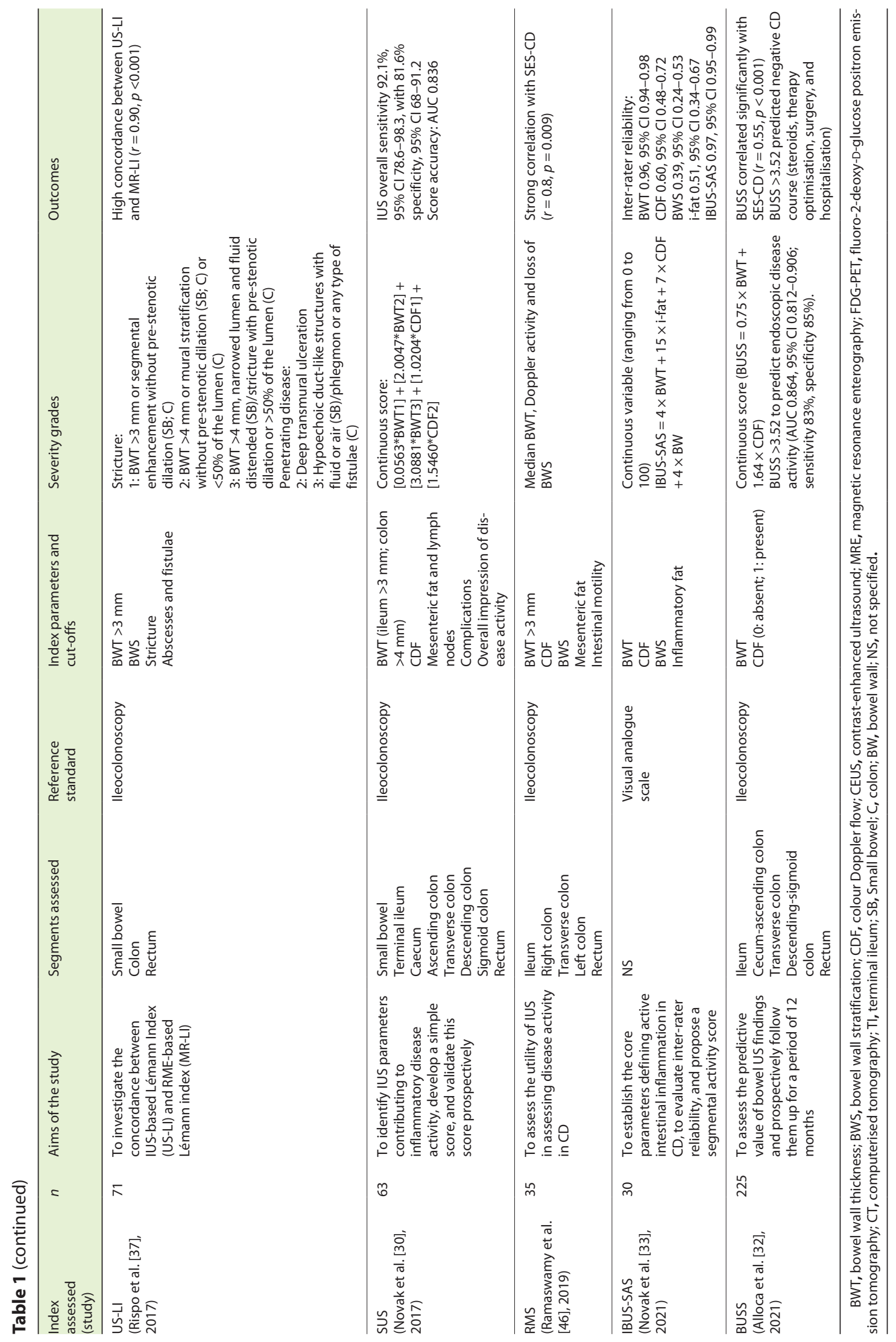


Several studies have assessed the value of BWT to support the diagnosis of UC [4]. Even though UC is a mucosal disease, a BWT $>4 \mathrm{~mm}$ had a sensitivity of $62-89 \%$ and specificity of $77-88 \%$ for its diagnosis [4]. Nevertheless, the best cut-off at diagnosis is not established and values $>3 \mathrm{~mm}$ have also been reported.

In patients with active IBD, UC patients have a prominent thickening of the mucosal layer, whereas $\mathrm{CD}$ patients have a significant thickening of the submucosal layer and a higher rate of lymph node enlargement [14]. In UC, the thickening of the bowel wall is mostly proportional and BWS is usually present [11]. The mesenteric proliferation is a prominent feature in $\mathrm{CD}$, although it can also occur in UC, especially during severe episodes [11]. Hence, IUS is an accurate method to screen for intestinal inflammation and to support the diagnosis of both CD and UC.

\section{Evaluating Disease Activity in IBD}

\section{Disease Activity and Postoperative Recurrence in Crohn's Disease}

IUS has shown a good accuracy in detecting disease activity in CD. In a systematic review, the overall sensitivity of IUS for assessing CD activity when compared to ileocolonoscopy, barium-contrasted exams, CT, MRE, capsule endoscopy, or surgical specimens was $89 \%$, with a specificity of $94.3 \%$ [5], as previously reported [15]. When compared to MRE, IUS has an accuracy of $91 \%$ for localisation and $89 \%$ for bowel wall flow [16]. Similarly, in a recent prospective study, the accuracy of IUS was not significantly different from MRE, regarding BWT, loss of BWS and $\mathrm{CDF}$, also highlighting the concordance between IUS and other cross-sectional exams [17]. The METRIC trial was a prospective multicentre trial including 284 patients (133 newly diagnosed; 151 relapsed) to evaluate MRE and IUS performance in assessing disease extent and activity in CD. A constructed referenced standard was used to compare the two techniques. Both MRE and IUS were highly accurate for detecting small bowel disease, even though a higher sensitivity and specificity in detecting disease activity and evaluating disease extent was observed with MRE [18]. Nonetheless, an expert panel highlighted some methodological limitations of this study such as bias in the constructed reference standard model, absence of information on time between MRE and IUS, and use of high BWT cutoffs [19]. Importantly, the sensitivity of IUS seems to be lower for jejunal lesions (55.6\%) when compared to ileal $(92.7 \%)$ or colonic involvement (81.8\%) [5].
Regarding postoperative recurrence, even though ileocolonoscopy remains the gold standard examination, non-invasive tools may be considered, especially after small bowel resection [20]. In a recent systematic review, the pooled IUS sensitivity and specificity for detecting postoperative recurrence was 94 and 84\% [21]. Small intestine contrast ultrasonography (SICUS) had a higher sensitivity ( 99 vs $82 \%$ ), but lower specificity ( 74 vs. $88 \%$ ) than IUS. Also, a higher concordance between contrastenhanced ultrasound (CEUS) and colonoscopy has been observed when compared to IUS alone ( $k=0.82$ vs. 0.64 , $p<0.001$ ), suggesting that both SICUS and CEUS can improve anastomosis evaluation [22]. Moreover, perianastomotic BWT correlated with Rutgeerts' endoscopic score ( $r=0.67, p=0.0001)$, with higher BWT in patients with a score $\geq i 3$ [23]. A cut-off BWT above $5.5 \mathrm{~mm}$ predicted severe endoscopic recurrence $(\geq \mathrm{i} 3)$ [21].

Finally, a growing interest has emerged with the use of transperineal ultrasound (TPUS) to assess perianal disease as a simple and painless method. TPUS showed a sensitivity of $90.6 \%$ and a positive predictive value (PPV) of $93.4 \%$ in detecting perianal fistulae when compared to pelvic MR [24]. Extrasphincteric and suprasphincteric fistulae were less detected by TPUS, when compared to transsphincteric and rectovaginal/anovulvar fistulae. Regarding perianal abscesses, TPUS showed a sensitivity of $50 \%$ and PPV of 79\% [25]. Importantly, although not completely studied, the steep learning curve of TPUS may limit the current use of this resource in clinical practice [26]. According to previous studies, physicians may achieve competency in TPUS after 12 months of training [27].

Accompanying the increasing evidence of IUS as an accurate tool to assess disease activity, several IUS scores have been published (Table 1). Six studies [28-33] evaluated inflammatory disease activity and showed a strong correlation between IUS score and endoscopy $[28,29,31$, 32]. Additionally, an expert consensus developed the International Bowel Ultrasound Segmental Activity Score (IBUS-SAS), with an almost perfect intraclass correlation coefficient (ICC 0.97 [0.95-0.99], $p<0.001$ ) [33]. Nevertheless, the BWT definition varied between the studies, ranging from $3 \mathrm{~mm}$ [28], to $4 \mathrm{~mm}$ [29], or even $5 \mathrm{~mm}$ [31] in the colon. Additionally, two studies evaluated postoperative recurrence $[22,34]$, two compared stricture detection and echo pattern between IUS and MRE or histology $[35,36]$, and one investigated the concordance between IUS and MRE scores based on the Lémann index (LI) [37]. Interestingly, a high concordance was found between US-LI and MR-LI $(r=0.90, p<0.001)$, suggesting 


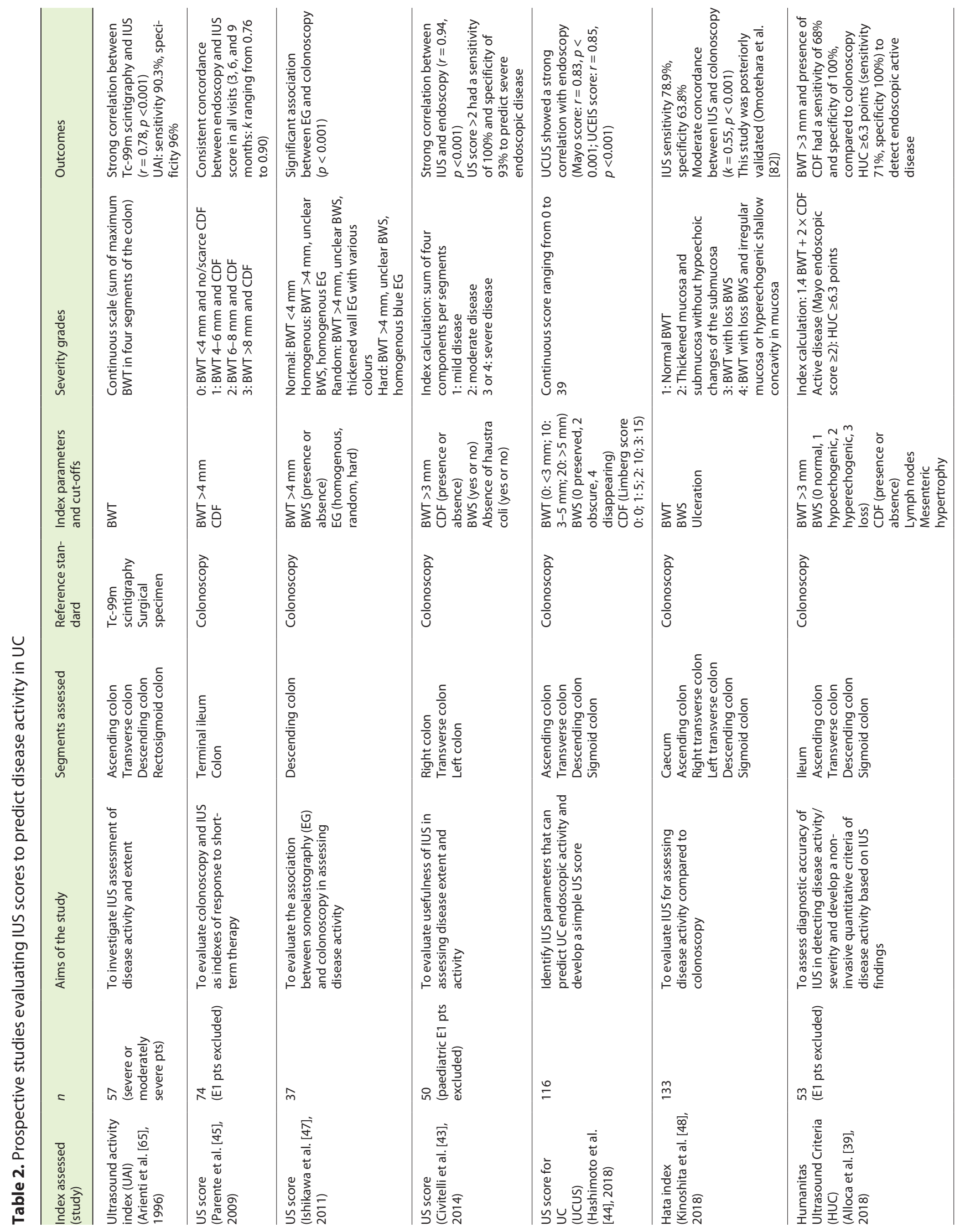




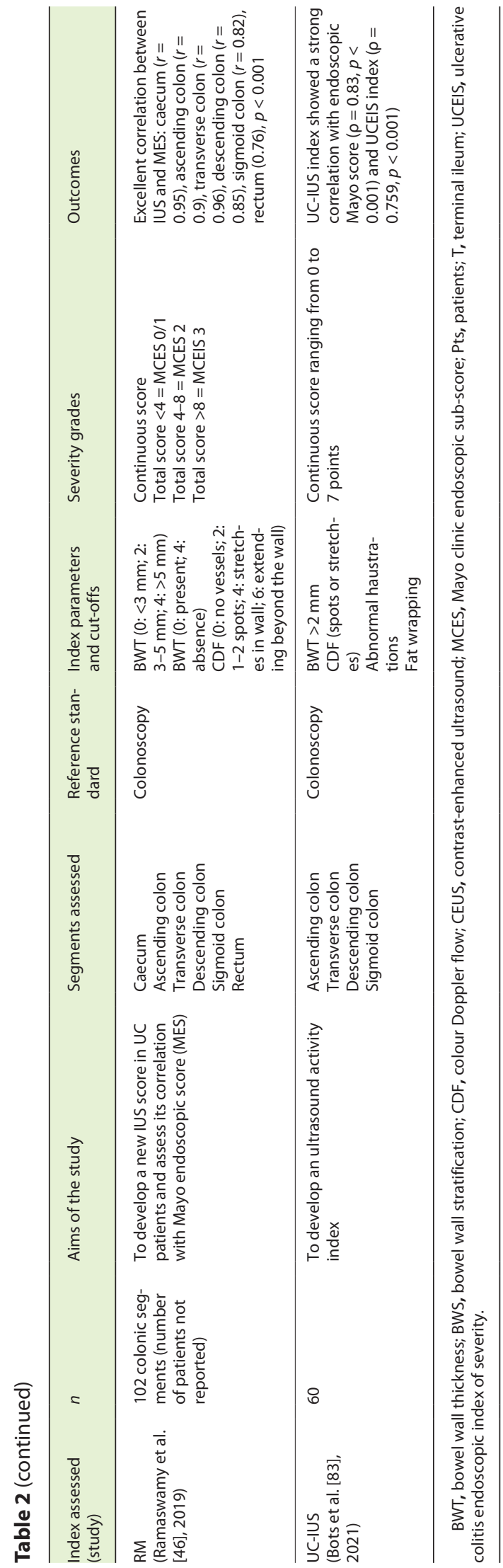

that IUS was not inferior to MRE to evaluate bowel damage.

Therefore, IUS is an accurate method to assess disease activity, even though a lower sensitivity when evaluating the jejunum has been shown. Regarding the postoperative setting, IUS is a useful method in detecting and grading the severity of recurrence in CD. Nevertheless, for patients with BWT $<5.5 \mathrm{~mm}$, IUS alone may not be sufficient to guide their management, as an accurate distinction between cicatrisation and mild to moderate recurrence may not be achieved and, therefore, cannot replace endoscopy yet [38]. Finally, several endoscopic scores have been developed but none is fully validated. Accordingly, no specific IUS score is currently recommended to evaluate $\mathrm{CD}$.

\section{Disease Activity in UC}

Although the role of IUS is less well established in UC, its value in evaluating disease activity has also been explored. In a prospective study, 53 UC patients underwent colonoscopy and IUS within 1 week. Patients with endoscopic active disease had higher BWT, presence of CDF, loss of BWS, and enlarged lymph nodes [39]. In a recent systematic review, most studies showed an association between IUS findings, either defined by BWT alone or in combination with other features, and disease severity on endoscopy [4]. Moreover, the accuracy of IUS to evaluate disease extension compared to endoscopy was reported as $88.5-95 \%$ (sensitivity $95 \%$; specificity 96\%) [4]. Assessments of the sigmoid and descending colon had the higher accuracy [40], in contrast to the rectum, where transabdominal IUS had a poor sensitivity (15\%) [41]. Nevertheless, this limitation could be exceeded using TPUS. In a cross-sectional study, 57 UC patients underwent transabdominal and TPUS evaluation simultaneously, 7 days before or after colonoscopy. Rectal BWT ( $r=0.72, p<$ $0.001)$ and $\operatorname{CDF}(r=0.66, p<0.001)$ correlated well with the Mayo endoscopic score, suggesting that TPUS can be a good tool to evaluate patients with proctitis [42].

Considering IUS scores, nine indices have been prospectively developed in UC (Table 2). All studies were based on BWT and usually complemented by CDF [39, 43-46] and/or BWS [39, 4, 44, 46, 48]. Most studies considered a normal BWT when below $3 \mathrm{~mm}$, even though two studies considered $4 \mathrm{~mm}$ to define normal BWT [45, 47]. Overall sensitivity of UC scores ranged from 71 to $100 \%$ and specificity from 63.8 to $100 \%$. A strong correlation was found between IUS scores and endoscopy [43$45,47]$, especially in severe disease $(r=0.94, p<0.001)$ [43]. 
Thus, IUS has shown a good performance in assessing disease activity in UC, although a lower sensitivity has been reported when evaluating the rectum, which could be exceeded using TPUS. Similar to CD, no IUS score has been formally validated.

\section{Evaluating Disease-Related Complications}

\section{Crohn's Disease}

Several studies have assessed IUS accuracy to detect intestinal strictures, with a sensitivity ranging from 74.4 to $100 \%$ and a specificity of $63-100 \%[35,49-53]$. Strictures have been defined by a thickening and stiffness of the bowel wall, accompanied by a proximal dilation $>2.5 \mathrm{~cm}$ (Fig. 2) [54]. In a prospective study including 249 CD patients, the concordance between MRE and IUS for stricturing disease was high when compared to intraoperative findings $(k=0.86)$ [55]. SICUS seems to have higher sensitivity for detecting strictures when compared to IUS (89-94 vs. 74-76\%) [56, 57] and showed a good accuracy in detecting ileal stenosis and prestenotic dilation $[58,59]$. However, it is still not clear if IUS, including SICUS, can distinguish inflammatory from fibrotic stenosis. Nevertheless, assessment of the wall echo pattern at the stricture level may suggest the degree of fibrosis. Maconi et al. [35] concluded that strictures with a stratified echo pattern had a higher degree of fibrosis compared to those characterised by a hypoechoic echo pattern. Moreover, a reduced CDF has also been associated with a fibrotic phenotype [60]. Importantly, CEUS has also been reported as an adjuvant method to characterise strictures in CD. When compared to surgical specimens, the concordance between CEUS with inflammatory or fibrostenotic phenotype was good $(k=0.63)$, with a good correlation between sonographic and pathology scores for both inflammatory $(r=0.53, p=0.004)$ and fibrotic stenosis $(r=0.50$, $p=0.007)$ [60]. Finally, conflicting data have been published when evaluating sonoelastography as a possible method to distinguish fibrotic from inflammatory strictures in $\mathrm{CD}$, and this modality requires further investigation [61].

Penetrating disease is another potential complication in CD. Abscess appears as an irregular hypoechoic lesion without vascularisation. Fistulae are hypoechoic tracts, originating from the bowel wall and connecting to other tissues, such as the urinary bladder, skin, vagina, or other intestinal segments (Fig. 3) [54]. In a meta-analysis, the pooled sensitivity and specificity of IUS in detecting fis-

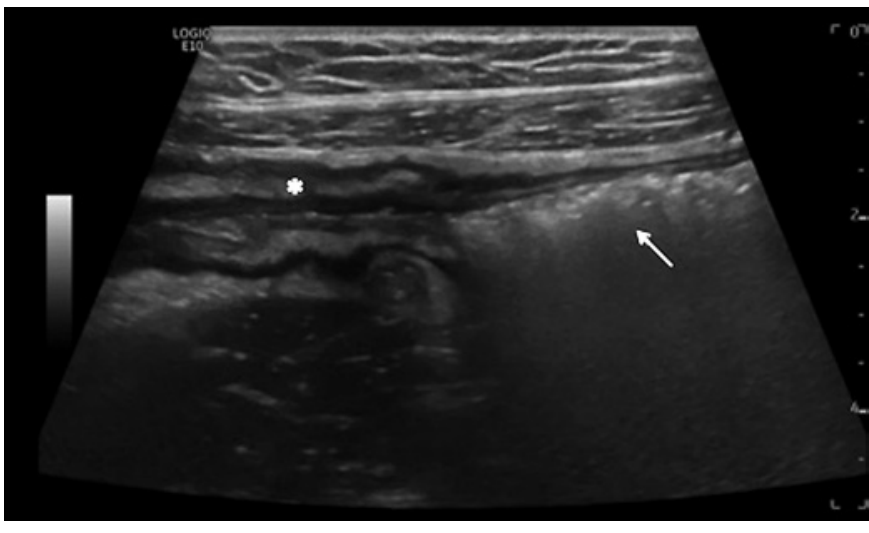

Fig. 2. IUS showing an ileal stenosis, with thickened bowel wall with narrow lumen (asterisk) and prestenotic dilation (arrow).

tulae was 74 and $95 \%$ and in diagnosing abscesses was 84 and $93 \%$, respectively [15]. Ripollés et al. [62] showed that CEUS was able to differentiate between phlegmon and abscess in $57 \mathrm{CD}$ patients, showing a high concordance $(k$ $=0.972$ ) with CT, MR, percutaneous drainage, or surgery. Similar findings have been previously reported, highlighting the role of CEUS as a sensitive method for differential diagnosis between phlegmon and abscess (Fig. 4) [63].

Therefore, IUS is an accurate method to evaluate CDrelated complications. SICUS can help evaluating patients with strictures. CEUS supports the differential diagnosis of an inflammatory mass and is a promising tool in differentiating inflammatory from fibrotic strictures.

\section{Ulcerative Colitis}

A particular important scenario is acute severe UC (ASUC), treated with high-dose systemic corticosteroids, which is associated with an increased risk of colectomy. Nowadays, therapy response is based on clinical symptoms and biochemical markers (Oxford criteria) [64]. In hospitalised patients with moderate to severe UC, a significant decrease in BWT was observed in all patients who did not require colectomy, whereas patients who underwent colectomy had no BWT improvement between admission until day 10 [65]. In a recent pilot study including 10 patients, higher BWT (6.2 vs. $4.6 \mathrm{~mm}, p=0.009$ ) and any colonic segment with BWT $>6 \mathrm{~mm}$ at admission were also associated with the need for infliximab salvage therapy. Additionally, after 3 days of high-dose steroid therapy, steroid-responsive patients had lower BWT (4.0 vs. $6.3 \mathrm{~mm}, p=0.009$ ) [66]. Similarly, in a retrospective study including 69 ASUC episodes in 52 paediatric patients, sal- 

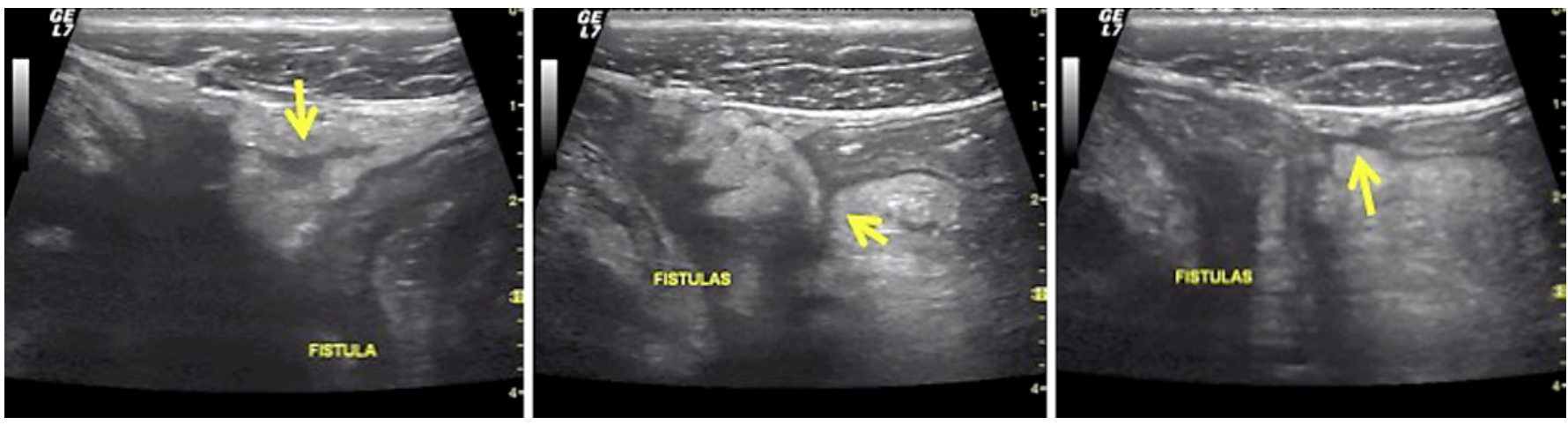

Fig. 3. IUS showing entero-enteric fistulae: hypoechoic tracts connecting small bowel loops (arrows).

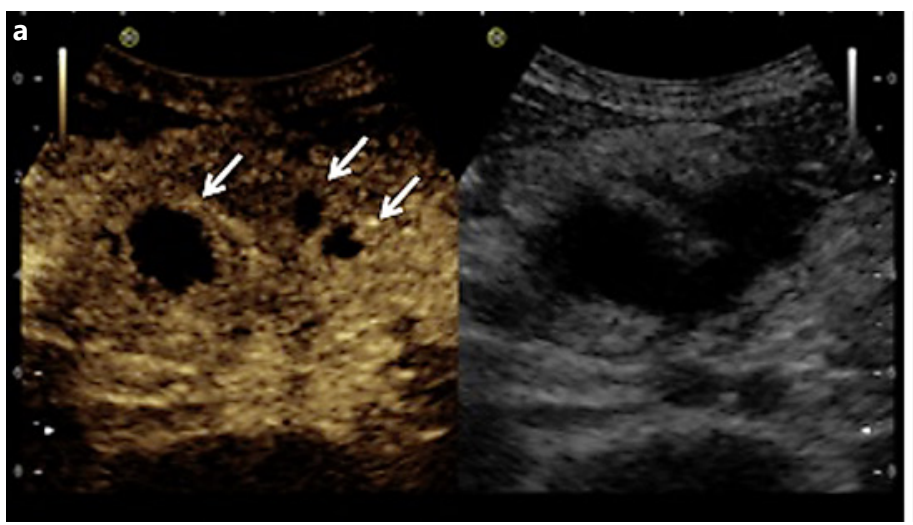

Fig. 4. Two examples of CEUS showing differentiation between abscess and inflammatory mass. a Using CEUS this hypoechoic mass shows three areas completely devoid of microbubble signal, repre-

vage therapy was more frequently needed in patients with higher BWT, higher vascularisation, and loss of BWS at admission. A thickened wall $(>3.4 \mathrm{~mm})$ and loss of BWS were independent predictors of steroid resistance [67]. Thus, if IUS parameters prove to be independent predictors of response to systemic steroids in the ASUC setting, early IUS could enable a timelier introduction of salvage therapy.

\section{Monitoring Response to Therapy}

\section{Crohn's Disease}

Several studies have assessed IUS as a monitoring tool in $\mathrm{CD}$ to evaluate the response to therapy [45, 68-70]. The definition of ultrasonographic remission, or transmural healing (TH), is not yet established, although it has been defined by some authors as a complete normalisation of

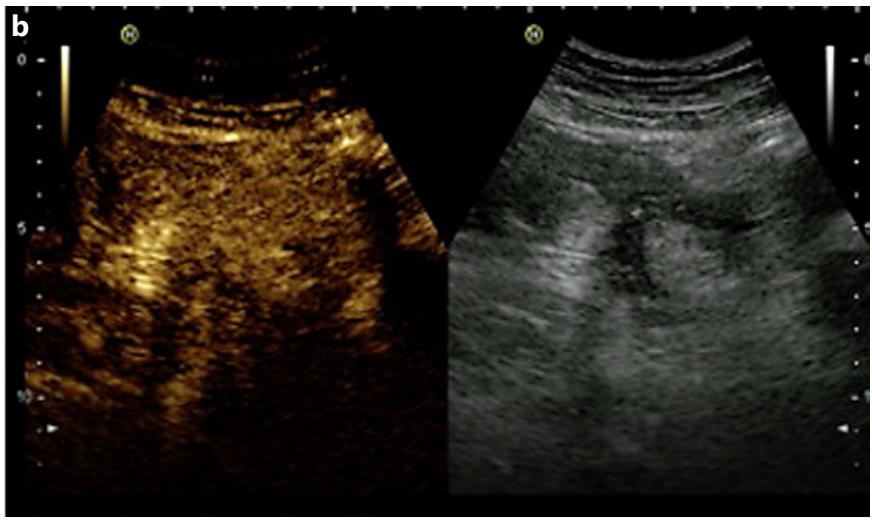

senting three abscesses. CEUS can be very helpful for defining the size of the abscesses. $\mathbf{b}$ Using CEUS this hypoechoic structure shows intralesional enhancement and corresponds to an inflammatory mass.

BWT ( $<3 \mathrm{~mm}$ ) with normal CDF or a complete normalisation of all IUS parameters. Additionally, definitions for ultrasonographic response have also been proposed when a sonographic improvement occurs [71]. In a prospective study, TH was associated with higher rates of steroid-free remission, lower rates of clinical relapse, and longer intervals until hospitalisation when compared to $\mathrm{MH}$, suggesting that $\mathrm{TH}$ may be a more accurate target than $\mathrm{MH}$ alone in CD [72]. In the recently published STRIDE-II update, TH is considered as a potential therapeutic target but not a formal one yet [1].

The TRUST study was a 12-month prospective study to assess the value of IUS in monitoring CD, including 243 patients with at least moderately active CD (Harvey Bradshaw index $>7$ ). A significant proportion of patients had an improvement in BWT, CDF, BWS, and mesenteric fat proliferation at the end of follow-up. These ultrasonographic changes were accompanied by 


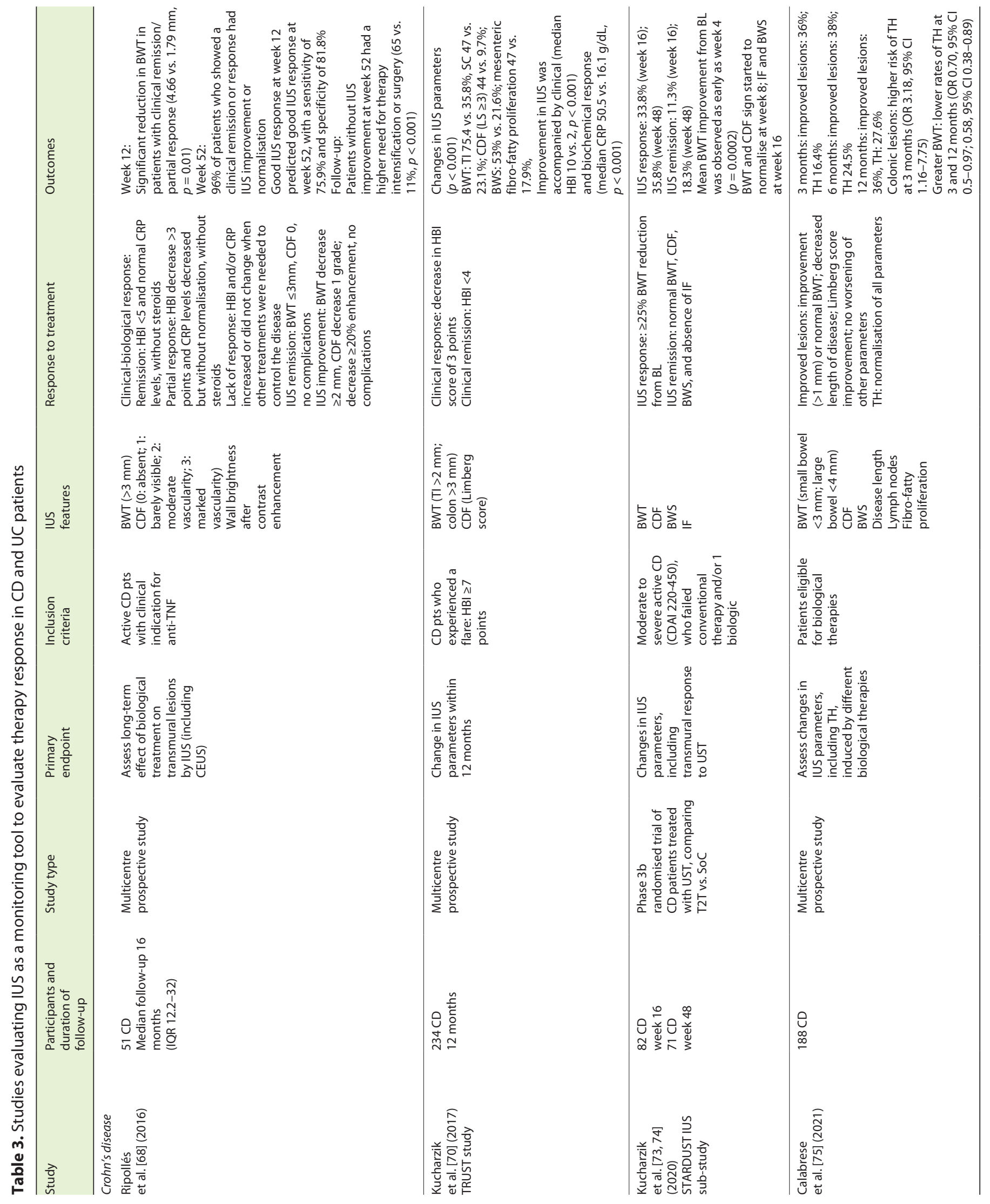




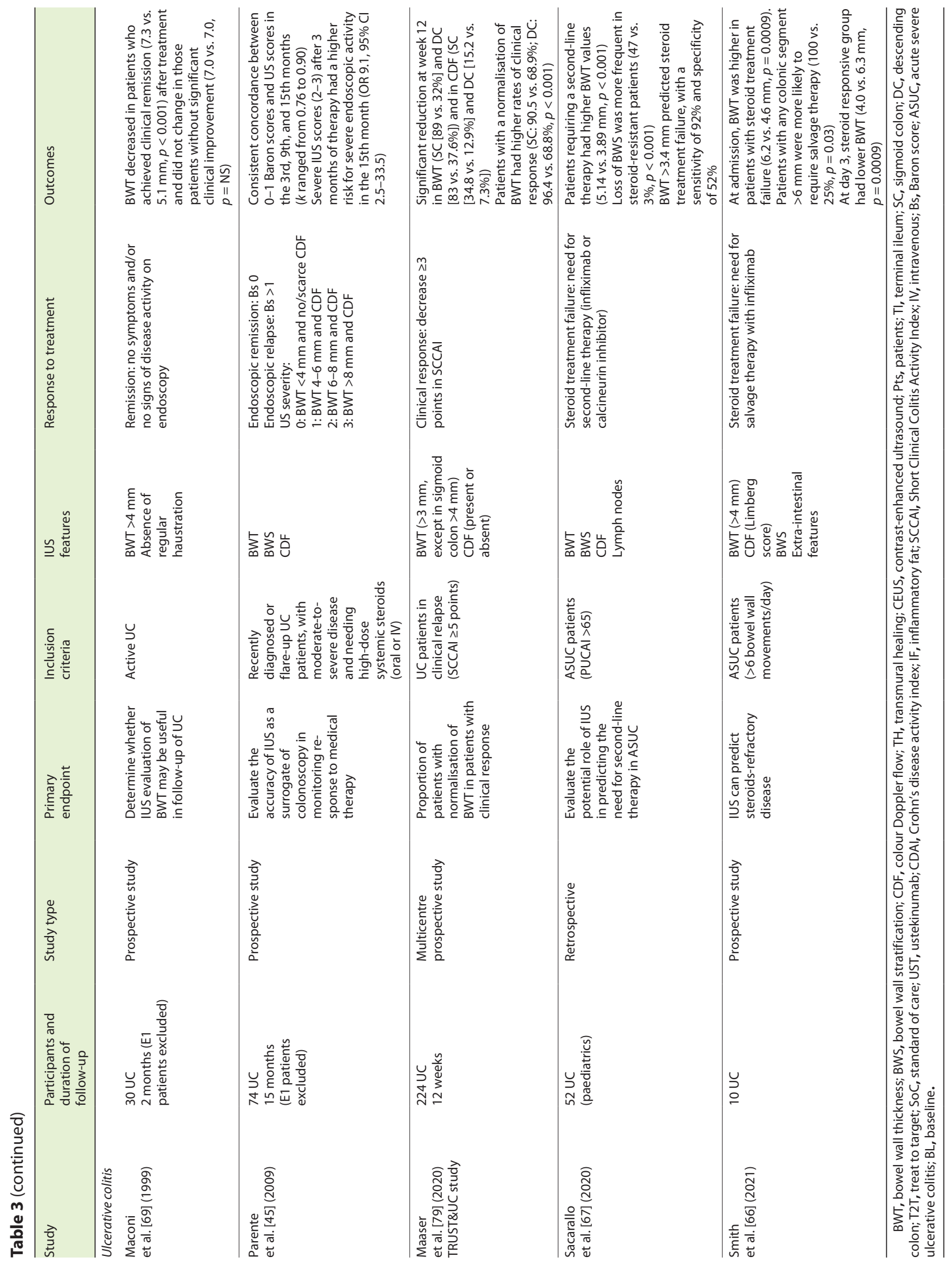


clinical and biochemical improvement [70]. Similarly, in a multicentre prospective study, improvement of BWT and CDF were observed after 12 weeks, increasing even more after 12 months of therapy, highlighting that IUS response at week 12 was associated with maintenance of the IUS response at week 52 [68]. Importantly, patients without IUS improvement after 1 year of therapy had a higher need for therapy intensification or surgery ( 65 vs. $11 \%, p<0.001$ ) [68]. Likewise, in an interim analysis of the STARDUST trial IUS sub-study including $88 \mathrm{CD}$ patients, IUS response and remission after ustekinumab induction were assessed. IUS response was defined by a BWT reduction of $25 \%$ from baseline and IUS remission by normalisation of BWT, CDF, BWS, and inflammatory mesenteric fat. At week 16, IUS response and remission rates were 33.8 and $11.3 \%$, respectively. BWT improvement was observed as early as week 4 , suggesting that IUS could be a useful method to detect early response to treatment [73]. A consistent decrease in BWT was observed up to week 48. Furthermore, the overall IUS response progressively increased over time (week $4846.3 \%$ ), accompanied by a higher rate of TH (week 48 24.1\%). Interestingly, normalisation of BWT was more frequent when the colon was affected compared to the ileum ( 50 vs. $15.8 \%$ at week 48 ), reflecting a faster cicatrisation of the colon [74]. A recent multicentre prospective study, including $181 \mathrm{CD}$ patients treated with different types of biologic therapies, assessed IUS improvement (decrease $\geq 1 \mathrm{~mm}$ or normalisation of BWT, decrease in length of disease, Limberg score improvement, and no worsening of other IUS parameters) and TH (normalisation of all parameters) during 12 months of follow-up. After 3 and 12 months, 36.7 and $36 \%$ of the patients showed IUS improvement, with 16.4 and $27.6 \%$ achieving $\mathrm{TH}$, respectively. Patients in clinical and biochemical remission had higher rates of TH. Predictive factors of TH included colonic location (aOR 3.18, 95\% CI 1.11-9.10), whereas greater BWT at baseline was associated with lower rates of TH at 3 (aOR $0.70,95 \%$ CI $0.5-0.97$ ) and 12 months (aOR 0.58, 95\% CI 0.38-0.89) [75]. Similarly, in a recent prospective study, baseline BWT and $\mathrm{CDF}$, presence of disease-related complications, FCal $(>250 \mu \mathrm{g} / \mathrm{g})$, and male gender were associated with a higher need for steroids, optimisation therapy, hospitalisation, or surgery after 12-months of follow-up [31]. Thus, IUS features at baseline and IUS improvement during follow-up seem to be associated with diseaserelated outcomes. In a prospective study, including 80 consecutive CD patients, baseline and follow-up SICUS were performed (after a median of 18 months). Patients with IUS response (improvement or normalisation of BWT, decreased length of disease, without complications) had lower need for steroids, hospitalisation, and/ or surgeries at 1 and 5 years of follow-up [76]. Regarding CEUS, differences in kinetic parameters derived from time intensity curves, such as peak enhancement, wash-in perfusion index, wash-in and wash-out rate, significantly improved in patients with clinical or endoscopic response, after 6 weeks of therapy [77]. Similarly, in a prospective study of IBD patients treated with vedolizumab, amplitude-derived CEUS parameters of mural microvascularisation also decreased in clinical responders after 14 weeks of therapy [78]. Altogether, these data emphasise the role of IUS as a method for monitoring the response to treatment in CD patients (Table 3).

\section{Ulcerative Colitis}

In the TRUST\&UC prospective study, IUS findings in UC patients after initiating therapy for clinical relapse were evaluated during a 12-week period [79]. Overall, 178 patients with left-sided or pancolitis completed follow-up at week 12. Patients with normalisation of BWT in the sigmoid or descending colon had higher rates of clinical response. Moreover, clinical responders showed a significant reduction in BWT and CDF at week 12 . These changes could be observed as early as after 2 weeks of therapy [79]. Finally, other IUS parameters, such as mesenteric fat proliferation, BWS, haustration, and ascites also improved after 12 weeks. Clinical symptoms accompanied IUS improvement, with a lower Simple Clinical Colitis Activity Index (SCCAI) at week 12 (9 vs. 2 points, $p<0.001)$. Similarly, a higher proportion of patients with BWT normalisation at week 12 had normal FCal values $(<250 \mu \mathrm{g} / \mathrm{g}$; sigmoid colon: 48.9 vs. $22.2 \%, p=0.02$; descending colon: 50 vs. $25 \%, p=0.03$ ) [79]. Parente et al. [45] also evaluated moderate to severe UC patients during a 15 -month follow-up period. $\mathrm{Pa}$ tients who had severe IUS activity in the third month after corticosteroids therapy had a higher risk of severe endoscopic activity at 15 months (OR 9.1, 95\% CI 2.533.5; Table 3).

Even though studies with longer follow-up are needed, these data support the use of IUS as a non-invasive monitoring tool to assess therapy response in UC. Importantly, the IUS response can be observed as early as $2-4$ weeks after treatment initiation. 
Current role of IUS in IBD

Screening and diagnosis of IBD

Differential diagnosis with IBS and GI infections

Small bowel assessment in $C D$

Disease activity assessment in IBD

Evaluation and grading of disease activity and extent

Severe postoperative recurrence in $C D$

Perianal disease in CD-TPUS

Disease-related complications in CD

Strictures, fistula such as and inflammatory masses, such as phlegmon and abscesses Monitoring response to therapy in IBD

Future directions

Validation of IUS scores to allow its use in clinical practice and clinical trials Improve IUS assessment of mild to moderate CD postoperative recurrence

CEUS as a promising tool differentiating fibrotic from inflammatory strictures

Transmural healing as potential target in $C D$

Uniform time points for IUS evaluation based on a treat-to-target strategy

IUS in ASUC: predict need for salvage therapy and colectomy

Correlation of IUS with histology in UC

Fig. 5. The current role and future directions of IUS in IBD. ASUC, acute severe ulcerative colitis; $\mathrm{CD}$, Crohn's disease; GI, gastrointestinal; IBS, irritable bowel syndrome; TPUS, transperineal ultrasound; UC, ulcerative colitis.

\section{Future Directions and Conclusions}

Nowadays, IUS is a very useful tool in the management of IBD patients, with a good accuracy in detecting disease activity, extent, and complications in CD. Besides, although being a mucosal disease, recent published data also endorse its use in UC to assess disease activity and extension. Emerging data have supported the use of IUS as a promising tool to assess response to treatment in both UC and CD, reporting changes in IUS features as early as 2-4 weeks of treatment and that persist in short- and long-term follow-up (Fig. 5). In fact, this could lead to a paradigm change in IBD, as IUS can become a routinely used tool in the management of these patients in a pointof-care setting and enabling early intervention if needed. Nevertheless, the use of IUS is not yet universal and its performance is highly dependent in the operator's experience. Inter-observer agreement of IUS in UC and CD patients is excellent for BWT and good for CDF, with fair to moderate agreement in other IUS parameters, such as lymph nodes and inflammatory fat $[80,81]$. Moreover, IUS can have lower accuracy in specific bowel locations, such as the proximal jejunum and rectum. Other possible limitations of IUS include the patient's biotype, as evaluation in obese patients is difficult [82], evaluation of disease activity/extent in the postoperative setting, due to anatomical changes, and the lower capacity to detect superficial lesions in the small bowel. Therefore, it is important to train IBD-specialised gastroenterologists in this technique, as proposed by the International Bowel Ultrasound (IBUS) group. Additionally, future studies are needed to improve IUS capacity in differentiating the severity of endoscopic recurrence in the postoperative setting, as well as to deepen the knowledge on elastography and better characterisation of stricture subtype in CD. Regarding UC, the real accuracy of IUS to predict histologic remission has never been formally studied. In an era of strict endpoints like endoscopic Mayo score of zero or even histological remission, IUS parameters might not be sensitive enough to capture subtle inflammatory mucosal changes. Finally, no IUS score has been fully validated and a homogenous approach of IUS parameters is warranted to spread its use in IBD clinics and hospitals, as well as in clinical trials.

In conclusion, IUS is an accurate non-invasive monitoring tool not only to assess IBD diagnosis, disease extent, and activity in CD and UC, but also to monitor response to therapy. In experienced hands, IUS adds extraordinary value to the management of IBD patients.

\section{Acknowledgements}

We would like to thank Dr. Frauke Peterson from the University Teaching Hospital of Lueneburg, Germany, for kindly sharing her CEUS cases for this review paper.

\section{Statement of Ethics}

This article does not contain any studies with humans or animal subjects performed by the authors.

\section{Conflict of Interest Statement}

J.T. received speaker and consulting fees from Janssen and consulting fees from Arena Pharmaceuticals, and Gilead and Galapagos. C.P. received speaker and consulting fees from Janssen and Laboratórios Vitória.

\section{Funding Sources}

This review had no funding resources.

\section{Author Contributions}

All the authors made substantial contributions to the article. C.F.-G., J.T., and C.P. contributed to the manuscript concept and design. C.F.-G. drafted the article, and J.T. and C.P. made important revisions and contributions. All authors critically revised the manuscript. All authors have approved the final version of the manuscript. 
1 Turner D, Ricciuto A, Lewis A, D'Amico F, Dhaliwal J, Griffiths AM, et al.; International Organization for the Study of IBD. STRIDE-II: An Update on the Selecting Therapeutic Targets in Inflammatory Bowel Disease (STRIDE) Initiative of the International Organization for the Study of IBD (IOIBD): Determining Therapeutic Goals for Treat-to-Target strategies in IBD. Gastroenterology. 2021 Apr;160(5):1570-83.

2 Shah SC, Colombel JF, Sands BE, Narula N. Mucosal healing is associated with improved long-term outcomes of patients with ulcerative colitis: a systematic review and metaanalysis. Clin Gastroenterol Hepatol. 2016 Sep;14(9):1245-1255.e8.

3 Maaser C, Sturm A, Vavricka SR, Kucharzik T, Fiorino G, Annese V, et al.; European Crohn's and Colitis Organisation [ECCO] and the European Society of Gastrointestinal and Abdominal Radiology [ESGAR]. ECCOESGAR Guideline for Diagnostic Assessment in IBD Part 1: initial diagnosis, monitoring of known IBD, detection of complications. J Crohns Colitis. 2019 Feb;13(2):144-64.

4 Smith RL, Taylor KM, Friedman AB, Gibson RN, Gibson PR. Systematic Review: Clinical Utility of Gastrointestinal Ultrasound in the Diagnosis, Assessment and Management of Patients With Ulcerative Colitis. J Crohns Colitis. 2020 May;14(4):465-79.

5 Calabrese E, Maaser C, Zorzi F, Kannengiesser K, Hanauer SB, Bruining DH, et al. Bowel Ultrasonography in the Management of Crohn's Disease. A Review with Recommendations of an International Panel of Experts. Inflamm Bowel Dis. 2016 May;22(5):116883.

6 de Voogd FA, Verstockt B, Maaser C, Gecse $\mathrm{KB}$. Point-of-care intestinal ultrasonography in inflammatory bowel disease. Nat Rev Gastroenterol Hepatol. 2021 Apr;18(4):209-10.

7 Goodsall TM, Nguyen TM, Parker CE, Ma C, Andrews JM, Jairath V, et al. Systematic Review: Gastrointestinal Ultrasound Scoring Indices for Inflammatory Bowel Disease. J Crohns Colitis. 2021 Jan;15(1):125-42.

8 Astegiano M, Bresso F, Cammarota T, Sarno A, Robotti D, Demarchi B, et al. Abdominal pain and bowel dysfunction: diagnostic role of intestinal ultrasound. Eur J Gastroenterol Hepatol. 2001 Aug;13(8):927-31.

9 White LS, Campbell C, Lee A, Lord A, Graham RS. Intestinal ultrasound as first-line investigation in low risk gastrointestinal symptoms: a new model of care. Intern Med J. 2020 Nov;16:imj.15133.

10 Revzin MV, Moshiri M, Bokhari J, Pellerito JS, Menias C. Sonographic assessment of infectious diseases of the gastrointestinal tract: from scanning to diagnosis. Abdom Radiol. 2020 Feb;45(2):261-92.

11 Kucharzik T, Kannengiesser K, Petersen F. The use of ultrasound in inflammatory bowel disease. Ann Gastroenterol. 2017;30(2):13544.
12 Dong J, Wang H, Zhao J, Zhu W, Zhang L, Gong J, et al. Ultrasound as a diagnostic tool in detecting active Crohn's disease: a metaanalysis of prospective studies. Eur Radiol. 2014 Jan;24(1):26-33.

13 Bollegala N, Griller N, Bannerman H, Habal M, Nguyen GC. Ultrasound vs Endoscopy, Surgery, or Pathology for the Diagnosis of Small Bowel Crohn's Disease and its Complications. Inflamm Bowel Dis. 2019 Jul;25(8):1313-38.

14 Ellrichmann M, Wietzke-Braun P, Dhar S, Nikolaus S, Arlt A, Bethge J, et al. Endoscopic ultrasound of the colon for the differentiation of Crohn's disease and ulcerative colitis in comparison with healthy controls. Aliment Pharmacol Ther. 2014 Apr;39(8):82333.

15 Panés J, Bouzas R, Chaparro M, García-Sánchez V, Gisbert JP, Martínez de Guereñu B, et al. Systematic review: the use of ultrasonography, computed tomography and magnetic resonance imaging for the diagnosis, assessment of activity and abdominal complications of Crohn's disease. Aliment Pharmacol Ther. 2011 Jul;34(2):125-45.

16 Allocca M, Fiorino G, Bonifacio C, Furfaro F, Gilardi D, Argollo M, et al. Comparative Accuracy of Bowel Ultrasound Versus Magnetic Resonance Enterography in Combination With Colonoscopy in Assessing Crohn's Disease and Guiding Clinical Decision-making. J Crohns Colitis. 2018 Nov;12(11):1280-7.

17 Yuksel I, Kilincalp S, Coskun Y, Akinci H, Hamamci M, Alkan A. Diagnostic accuracy of intestinal ultrasound and magnetic resonance enterography for the detection of endoscopybased disease activity in ileocolonic Crohn's disease. Eur J Gastroenterol Hepatol. 2019 Jul;31(7):809-16.

18 Taylor SA, Mallett S, Bhatnagar G, BaldwinCleland R, Bloom S, Gupta A, et al.; METRIC study investigators. Diagnostic accuracy of magnetic resonance enterography and small bowel ultrasound for the extent and activity of newly diagnosed and relapsed Crohn's disease (METRIC): a multicentre trial. Lancet Gastroenterol Hepatol. 2018 Aug;3(8):54858.

19 Novak K, Maaser C, Wilkens R, Maconi G, Kucharzik T; International Bowel Ultrasound Group. Diagnostic accuracy of MRE and ultrasound for Crohn's disease. Lancet Gastroenterol Hepatol. 2019 Feb;4(2):95-6.

20 Sturm A, Maaser C, Calabrese E, Annese V, Fiorino G, Kucharzik T, et al.; European Crohn's and Colitis Organisation [ECCO] and the European Society of Gastrointestinal and Abdominal Radiology [ESGAR]. ECCOESGAR Guideline for Diagnostic Assessment in IBD Part 2: IBD scores and general principles and technical aspects. J Crohns Colitis. 2019 Mar;13(3):273-84.

21 Rispo A, Imperatore N, Testa A, Nardone OM, Luglio G, Caporaso N, et al. Diagnostic
Accuracy of Ultrasonography in the Detection of Postsurgical Recurrence in Crohn's Disease: A Systematic Review with Metaanalysis. Inflamm Bowel Dis. 2018 Apr;24(5):977-88.

22 Paredes JM, Ripollés T, Cortés X, Moreno N, Martínez MJ, Bustamante-Balén $M$, et al. Contrast-enhanced ultrasonography: usefulness in the assessment of postoperative recurrence of Crohn's disease. J Crohns Colitis. 2013 Apr;7(3):192-201.

23 Calabrese E, Petruzziello C, Onali S, Condino G, Zorzi F, Pallone F, et al. Severity of postoperative recurrence in Crohn's disease: correlation between endoscopic and sonographic findings. Inflamm Bowel Dis. 2009 Nov;15(11):1635-42.

24 Losco A, Viganò C, Conte D, Cesana BM, Basilisco G. Assessing the activity of perianal Crohn's disease: comparison of clinical indices and computer-assisted anal ultrasound. Inflamm Bowel Dis. 2009 May;15(5):742-9.

25 Maconi G, Tonolini M, Monteleone M, Bezzio C, Furfaro F, Villa C, et al. Transperineal perineal ultrasound versus magnetic resonance imaging in the assessment of perianal Crohn's disease. Inflamm Bowel Dis. 2013 Dec;19(13):2737-43.

26 Bezzio C, Bryant RV, Manes G, Maconi G, Saibeni S. New horizons in the imaging of perianal Crohn's disease: transperineal ultrasonography. Expert Rev Gastroenterol Hepatol. 2017 Jun;11(6):523-30.

27 Wright EK, Novak KL, Lu C, Panaccione R, Ghosh S, Wilson SR. Transperineal ultrasonography in perianal Crohn disease: A valuable imaging modality. Can J Gastroenterol Hepatol. 2015 Nov-Dec;29(8):445-7.

28 Kakkadasam Ramaswamy P, Vizhi N K, Yelsangikar A, Krishnamurthy AN, Bhat V, Bhat N. Utility of bowel ultrasound in assessing disease activity in Crohn's disease. Indian J Gastroenterol. 2020 Oct;39(5):495502.

29 Futagami Y, Haruma K, Hata J, Fujimura J, Tani H, Okamoto E, et al. Development and validation of an ultrasonographic activity index of Crohn's disease. Eur J Gastroenterol Hepatol. 1999 Sep;11(9):1007-12.

30 Novak KL, Kaplan GG, Panaccione R, Afshar EE, Tanyingoh D, Swain M, et al. A Simple Ultrasound Score for the Accurate Detection of Inflammatory Activity in Crohn's Disease. Inflamm Bowel Dis. 2017 Nov;23(11):200110.

31 Neye H, Voderholzer W, Rickes S, Weber J, Wermke W, Lochs H. Evaluation of criteria for the activity of Crohn's disease by power Doppler sonography. Dig Dis. 2004;22(1):6772.

32 Allocca M, Craviotto V, Bonovas S, Furfaro F, Zilli A, Peyrin-Biroulet L, et al. Predictive value of bowel ultrasound in Crohn's disease: a 12-month prospective study. Clin Gastroenterol Hepatol. 2021 Apr;22:S1542-3565. 
33 Novak KL, Nylund K, Maaser C, Petersen F, Kucharzik T, Lu C, et al. Expert Consensus on Optimal Acquisition and Development of the International Bowel Ultrasound Segmental Activity Score [IBUS-SAS]: A Reliability and Inter-rater Variability Study on Intestinal Ultrasonography in Crohn's Disease. J Crohns Colitis. 2021 Apr;15(4):609-16.

34 Paredes JM, Ripollés T, Cortés X, Reyes MD, López A, Martínez MJ, et al. Non-invasive diagnosis and grading of postsurgical endoscopic recurrence in Crohn's disease: usefulness of abdominal ultrasonography and leucocyte scintigraphy. J Crohns Colitis. 2010;4(5):537-45.

35 Maconi G, Carsana L, Fociani P, Sampietro GM, Ardizzone S, Cristaldi M, et al. Small bowel stenosis in Crohn's disease: clinical, biochemical and ultrasonographic evaluation of histological features. Aliment Pharmacol Ther. 2003 Oct;18(7):749-56.

36 Lenze F, Wessling J, Bremer J, Ullerich H, Spieker T, Weckesser M, et al. Detection and differentiation of inflammatory versus fibromatous Crohn's disease strictures: prospective comparison of $18 \mathrm{~F}-\mathrm{FDG}-\mathrm{PET} / \mathrm{CT}$, MR-enteroclysis, and transabdominal ultrasound versus endoscopic/histologic evaluation. Inflamm Bowel Dis. 2012 Dec;18(12):2252-60.

37 Rispo A, Imperatore N, Testa A, Mainenti P, De Palma GD, Luglio G, et al. Bowel Damage in Crohn's Disease: Direct Comparison of Ultrasonography-based and Magnetic Resonance-based Lemann Index. Inflamm Bowel Dis. 2017 Jan;23(1):143-51.

38 Fraquelli M, Castiglione F, Calabrese E, Maconi G. Impact of intestinal ultrasound on the management of patients with inflammatory bowel disease: how to apply scientific evidence to clinical practice. Dig Liver Dis. 2020 Jan;52(1):9-18.

39 Allocca M, Fiorino G, Bonovas S, Furfaro F, Gilardi D, Argollo M, et al. Accuracy of $\mathrm{Hu}-$ manitas Ultrasound Criteria in Assessing Disease Activity and Severity in Ulcerative Colitis: A Prospective Study. J Crohns Colitis. 2018 Nov;12(12):1385-91.

40 Pascu M, Roznowski AB, Müller HP, Adler A, Wiedenmann B, Dignass AU. Clinical relevance of transabdominal ultrasonography and magnetic resonance imaging in patients with inflammatory bowel disease of the terminal ileum and large bowel. Inflamm Bowel Dis. 2004 Jul;10(4):373-82.

41 Parente F, Greco S, Molteni M, Cucino C, Maconi G, Sampietro GM, et al. Role of early ultrasound in detecting inflammatory intestinal disorders and identifying their anatomical location within the bowel. Aliment Pharmacol Ther. 2003 Nov;18(10):1009-16.

42 Sagami S, Kobayashi T, Aihara K, Umeda M, Morikubo H, Matsubayashi M, et al. Transperineal ultrasound predicts endoscopic and histological healing in ulcerative colitis. Aliment Pharmacol Ther. 2020 Jun;51(12):137383.
43 Civitelli F, Di Nardo G, Oliva S, Nuti F, Ferrari F, Dilillo A, et al. Ultrasonography of the colon in pediatric ulcerative colitis: a prospective, blind, comparative study with colonoscopy. J Pediatr. 2014 Jul;165(1):78-84.e2.

44 Hashimoto Y, Kume N, Sato K, Kanemura T, Haga A, Ishii Y, et al. P331 Development of a novel transabdominal ultrasound disease activity score in patients with ulcerative colitis (UCUS score). J Crohns Colitis. 2018;12(suppl. 1):S269.

45 Parente F, Molteni M, Marino B, Colli A, Ardizzone S, Greco S, et al. Are colonoscopy and bowel ultrasound useful for assessing response to short-term therapy and predicting disease outcome of moderate-to-severe forms of ulcerative colitis?: a prospective study. Am J Gastroenterol. 2010 May;105(5):1150-7.

46 Ramaswamy KP, Yelsangikar A, Nagarajan KV, Nagar A, Bhat N. P154 Development of a novel ultrasound based score for assessing disease activity in ulcerative colitis: preliminary results. J Crohns Colitis. 2019;13(suppl. 1):S166.

47 Ishikawa $\mathrm{D}$, Ando $\mathrm{T}$, Watanabe $\mathrm{O}$, Ishiguro $\mathrm{K}$ Maeda O, Miyake N, et al. Images of colonic real-time tissue sonoelastography correlate with those of colonoscopy and may predict response to therapy in patients with ulcerative colitis. BMCGastroenterol.2011 Mar;11(1):29.

48 Kinoshita K, Katsurada T, Nishida M, Omotehara S, Onishi R, Mabe K, et al. Usefulness of transabdominal ultrasonography for assessing ulcerative colitis: a prospective, multicenter study. J Gastroenterol. 2019 Jun;54(6):521-9.

49 Maconi G, Bollani S, Bianchi Porro G. Ultrasonographic detection of intestinal complications in Crohn's disease. Dig Dis Sci. 1996 Aug;41(8):1643-8.

50 Kohn A, Cerro P, Milite G, De Angelis E, Prantera C. Prospective evaluation of transabdominal bowel sonography in the diagnosis of intestinal obstruction in Crohn's disease: comparison with plain abdominal film and small bowel enteroclysis. Inflamm Bowel Dis. 1999 Aug;5(3):153-7.

51 Gasche C, Moser G, Turetschek K, Schober E, Moeschl P, Oberhuber G. Transabdominal bowel sonography for the detection of intestinal complications in Crohn's disease. Gut. 1999 Jan;44(1):112-7.

52 Neye H, Ensberg D, Rauh P, Peitz U, Mönkemüller K, Treiber G, et al. Impact of high-resolution transabdominal ultrasound in the diagnosis of complications of Crohn's disease. Scand J Gastroenterol. 2010 Jun;45(6):690-5.

53 Parente F, Maconi G, Bollani S, Anderloni A, Sampietro G, Cristaldi M, et al. Bowel ultrasound in assessment of Crohn's disease and detection of related small bowel strictures: a prospective comparative study versus X-ray and intraoperative findings. Gut. 2002 Apr;50(4):490-5.

54 Kucharzik T, Maaser C. Intestinal ultrasound and management of small bowel Crohn's disease. Therap Adv Gastroenterol. 2018 May;11:1756284818771367.
55 Castiglione F, Mainenti PP, De Palma GD, Testa A, Bucci L, Pesce G, et al. Noninvasive diagnosis of small bowel Crohn's disease: direct comparison of bowel sonography and magnetic resonance enterography. Inflamm Bowel Dis. 2013 Apr;19(5):991-8.

56 Calabrese E, La Seta F, Buccellato A, Virdone R, Pallotta N, Corazziari E, et al. Crohn's disease: a comparative prospective study of transabdominal ultrasonography, small intestine contrast ultrasonography, and small bowel enema. Inflamm Bowel Dis. 2005 Feb;11(2):139-45.

57 Parente F, Greco S, Molteni M, Anderloni A, Sampietro GM, Danelli PG, et al. Oral contrast enhanced bowel ultrasonography in the assessment of small intestine Crohn's disease. A prospective comparison with conventional ultrasound, $\mathrm{x}$ ray studies, and ileocolonoscopy. Gut. 2004 Nov;53(11):1652-7.

58 Pallotta N, Vincoli G, Montesani C, Chirletti $\mathrm{P}$, Pronio A, Caronna R, et al. Small intestine contrast ultrasonography (SICUS) for the detection of small bowel complications in crohn's disease: a prospective comparative study versus intraoperative findings. Inflamm Bowel Dis. 2012 Jan;18(1):74-84.

59 Calabrese E, Zorzi F, Onali S, Stasi E, Fiori R, Prencipe S, et al. Accuracy of small-intestine contrast ultrasonography, compared with computed tomography enteroclysis, in characterizing lesions in patients with Crohn's disease. Clin Gastroenterol Hepatol. 2013 Aug;11(8):950-5.

60 Ripollés T, Rausell N, Paredes JM, Grau E, Martínez MJ, Vizuete J. Effectiveness of contrast-enhanced ultrasound for characterisation of intestinal inflammation in Crohn's disease: a comparison with surgical histopathology analysis. J Crohns Colitis. 2013 Mar;7(2):120-8.

61 Bettenworth D, Bokemeyer A, Baker M, Mao R, Parker CE, Nguyen T, et al.; Stenosis Therapy and Anti-Fibrotic Research (STAR) Consortium. Assessment of Crohn's disease-associated small bowel strictures and fibrosis on cross-sectional imaging: a systematic review. Gut. 2019 Jun;68(6):1115-26.

62 Ripollés T, Martínez-Pérez MJ, Paredes JM, Vizuete J, García-Martínez E, Jiménez-Restrepo DH. Contrast-enhanced ultrasound in the differentiation between phlegmon and abscess in Crohn's disease and other abdominal conditions. Eur J Radiol.2013 Oct;82(10):e525-31.

63 Esteban JM, Aleixandre A, Hurtado MJ, Maldonado L, Mora FJ, Nogués E. Contrast-enhanced power Doppler ultrasound in the diagnosis and follow-up of inflammatory abdominal masses in Crohn's disease. Eur J Gastroenterol Hepatol. 2003 Mar;15(3):253-9.

64 Harbord M, Eliakim R, Bettenworth D, Karmiris K, Katsanos K, Kopylov U, et al.; European Crohn's and Colitis Organisation [ECCO]. Third European Evidence-based Consensus on Diagnosis and Management of Ulcerative Colitis. Part 2: current Management. J Crohns Colitis. 2017 Jul;11(7):769-84. 
65 Arienti V, Campieri M, Boriani L, Gionchetti P, Califano C, Giancane S, et al. Management of severe ulcerative colitis with the help of high resolution ultrasonography. Am J Gastroenterol. 1996 Oct;91(10):2163-9.

66 Smith R, Taylor K, Friedman A, Swaine A, Gibson D, Gibson P. Early assessment with gastrointestinal ultrasound in patients hospitalised for a flare of ulcerative colitis and predicting the need for salvage therapy: a pilot study. Ultrasound Med Biol. 2021;(5):S03015629-3.

67 Scarallo L, Maniscalco V, Paci M, Renzo S, Naldini S, Barp J, et al. Bowel Ultrasound Scan Predicts Corticosteroid Failure in Children With Acute Severe Colitis. J Pediatr Gastroenterol Nutr. 2020 Jul;71(1):46-51.

68 Ripollés T, Paredes JM, Martínez-Pérez MJ, Rimola J, Jauregui-Amezaga A, Bouzas R, et al. Ultrasonographic Changes at 12 Weeks of Anti-TNF Drugs Predict 1-year Sonographic Response and Clinical Outcome in Crohn's Disease: A Multicenter Study. Inflamm Bowel Dis. 2016 Oct;22(10):2465-73.

69 Maconi G, Ardizzone S, Parente F, Bianchi Porro G. Ultrasonography in the evaluation of extension, activity, and follow-up of ulcerative colitis. Scand J Gastroenterol. 1999 Nov;34(11):1103-7.

70 Kucharzik T, Wittig BM, Helwig U, Börner N, Rössler A, Rath S, et al.; TRUST study group. Use of Intestinal Ultrasound to Monitor Crohn's Disease Activity. Clin Gastroenterol Hepatol. 2017 Apr;15(4):535-542.e2.
71 Paredes JM, Ripollés T, Cortés X, Martínez MJ, Barrachina M, Gómez F, et al. Abdominal sonographic changes after antibody to tumor necrosis factor (anti-TNF) alpha therapy in Crohn's Disease. Dig Dis Sci. 2010 Feb;55(2):404-10.

72 Castiglione F, Imperatore N, Testa A, De Palma GD, Nardone OM, Pellegrini L, et al. Oneyear clinical outcomes with biologics in Crohn's disease: transmural healing compared with mucosal or no healing. Aliment Pharmacol Ther. 2019 Apr;49(8):1026-39.

73 Kucharzik T, Wilkens R, Maconi G, D’Agostino MA, Le Bars M, Nazar M, et al. DOP10 Intestinal ultrasound response and transmural healing after ustekinumab induction in Crohn's disease: Week 16 interim analysis of the STARDUST trial substudy. J Crohns Colitis. 2020;14 Suppl 1:S046-8.

74 Kucharzik T, Wilkens R, Maconi G, et al. LB12 Intestinal ultrasound response and transmural healing after 48 weeks of treatment with ustekinumab in Crohn's disease: STARDUST trial substudy. United European Gastroenterol J. 2020;8(10):1258-75.

75 Calabrese E, Rispo A, Zorzi F, et al. Ultrasonography tight control and monitoring in Crohn's disease during different biological therapies: a multicenter study. Clin Gastroenterol Hepatol. 2021;21:S1542-3565.

76 Zorzi F, Ghosh S, Chiaramonte C, Lolli E, Ventura M, Onali S, et al. Response Assessed by Ultrasonography as Target of Biological Treatment for Crohn's Disease. Clin Gastroenterol Hepatol. 2020 Aug;18(9):2030-7.

77 Quaia E, Gennari AG, Cova MA. Early Predictors of the Long-term Response to Therapy in Patients With Crohn Disease Derived From a Time-Intensity Curve Analysis After Microbubble Contrast Agent Injection. J Ultrasound Med. 2019 Apr;38(4):947-58.
78 Goertz RS, Klett D, Wildner D, Atreya R, Neurath MF, Strobel D. Quantitative contrast-enhanced ultrasound for monitoring vedolizumab therapy in inflammatory bowel disease patients: a pilot study. Acta Radiol. 2018 Oct;59(10):1149-56.

79 Maser C, Petersen F, Helwig U, Fischer I, Roessler A, Rath S, et al.; German IBD Study Group and the TRUST\&UC study group; German IBD Study Group and TRUST\&UC study group. Intestinal ultrasound for monitoring therapeutic response in patients with ulcerative colitis: results from the TRUST\&UC study. Gut. 2020 Sep;69(9):1629-36

80 Fraquelli M, Sarno A, Girelli C, Laudi C, Buscarini E, Villa C, et al. Reproducibility of bowel ultrasonography in the evaluation of Crohn's disease. Dig Liver Dis. 2008 Nov;40(11):860-6.

81 De Voogd F, Wilkens R, Gecse K, Allocca M, Novak K, Lu C, et al. A reliability study: strong inter-observer agreement of an expert panel for intestinal ultrasound in ulcerative colitis. J Crohns Colitis. 2021 Aug;15(8):1284-90.

82 Calabrese E. Bowel ultrasound for the assessment of Crohn's disease. Gastroenterol Hepatol (N Y). 2011 Feb;7(2):107-9.

83 Bots S, Nylund K, Lowenberg M, Gecse K, D'Haens G. Intestinal ultrasound to assess disease activity in ulcerative colitis: development of a novel UC-ultrasound index. J Crohns Colitis. 2021;7(8):1264-71.

84 Omotehara S, Nishida M, Kinoshita K, et al. Validation of US evaluation of ulcerative colitis activity. Ultrasound Med Biol. 2019; 45(7):1537-44. 